\title{
A comparison of devices using thermal desorption for mercury speciation in solids
}

M. Rumayor ${ }^{\mathrm{a}}$, M. A. Lopez-Anton ${ }^{\mathrm{a} *}$, M. Díaz-Somoano ${ }^{\mathrm{a}}$, M. M. Maroto-Valer ${ }^{\mathrm{b}}, \mathrm{J}-\mathrm{H}$. Richard $^{\mathrm{c}}$, H. Biester ${ }^{\mathrm{c}}$, M. R. Martínez-Tarazona ${ }^{\mathrm{a}}$

${ }^{a}$ Instituto Nacional del Carbón (CSIC), Francisco Pintado Fe, 26, 33011, Oviedo, Spain

${ }^{\mathrm{b}}$ Centre for Innovation in Carbon Capture and Storage (CICCS), School of Engineering \& Physical Sciences, Heriot-Watt University, Edinburgh, EH14 4AS, United Kingdom

${ }^{\mathrm{c}}$ Technische Universität Braunschweig, Institut für Geoökologie, Langer Kamp 19c, 38106 Braunschweig, Germany

*Corresponding author:

Phone: +34 985119090

Fax: +34985297662

Email:

marian@,incar.csic.es 


\section{Abstract}

The goal of this work is to emphasize the reliability of the thermal desorption technique in identifying mercury species. The analysis of mercury species in solids is essential for assessing the risk of disposal or re-use of mercury-contaminated materials. This study evaluates the accuracy and reliability of thermal desorption as a technique for identifying mercury species by means of different thermo-desorption devices. For this purpose, mercury species present in samples related with coal utilization processes were identified. Three devices were compared for analyzing samples free of carbon or with a low carbon content (fly ashes, gypsums and soils), and a new equipment was developed to analyze samples with a high carbon content (coal). In spite of the fact that the first three devices employ different experimental conditions (i.e., heating rate, gas flow and carrier gas), the mercury species identified in the samples were comparable in all cases. The need for new equipment for mercury speciation in materials containing carbon was a consequence of interferences produced from the pyrolysis products of the organic matter. The new device consists of two furnaces and two gas inlets to allow thermal oxidation of organic pyrolysis products and the identification of mercury species in carbonaceous samples. This new approach offers the application of thermal desorption to mercury speciation in all types of materials contaminated with mercury.

Keywords: mercury; speciation; coal; thermal desorption 


\section{Introduction}

Mercury $(\mathrm{Hg})$ is a metal with unique characteristics. Its high vapor pressure and surface tension facilitates its distribution in the atmosphere, causing widespread contamination. Although $\mathrm{Hg}$ is found in nature in the form of cinnabar (red $\mathrm{HgS}$ ), metacinnabar (black $\mathrm{HgS})$, livingstonite $\left(\mathrm{HgSb}_{4} \mathrm{~S}_{7}\right)$, coloradite $(\mathrm{HgTe})$, tiemannite ( $\mathrm{HgSe})$ and calomel $\left(\mathrm{Hg}_{2} \mathrm{Cl}_{2}\right)$, human activity has changed the global $\mathrm{Hg}$ cycle and increased the amount of mercury that people can be exposed to. Mercury entering water, soil and atmosphere from anthropogenic emissions is in the form of elemental mercury $\left(\mathrm{Hg}^{0}\right)$, inorganic mercury $\left(\mathrm{Hg}^{2+}\right.$ and $\left.\mathrm{Hg}^{+}\right)$and organic mercury. Inorganic mercury is linked to sulfide, chloride, nitrate, oxide or sulfate. Depending on the source and the environmental conditions, mercury can be transformed into different forms that show distinct behaviors, bioavailability and toxicity. Therefore, it is essential to know the chemical form of this element in order to be able to predict its behavior in the ecosystem and find suitable remediation methods for its control.

Coal combustion is the main anthropogenic source of mercury emissions, followed by metal smelting, cement production and waste incineration [1-3]. The emissions of mercury from thermal power stations and other combustion installations account for $55.4 \%$ of the total amount of mercury emitted in Europe in 2012 [4]. Coal fired power plants also generate $\mathrm{Hg}$-loaded solid wastes [5], such as fly ashes and gypsum. These sub-products are disposed of in landfills or re-used as raw materials, with the consequent risk of being released to water or to the atmosphere. The environmental impact of mercury depends on the mode of occurrence in these solids. 
Mercury speciation in solids can be measured via different techniques. X-ray absorption Spectroscopy (EXAFS) is a powerful technique that provides detailed information about the form and neighboring atoms of $\mathrm{Hg}$. However, EXAFS is generally effective in samples with concentrations of $\mathrm{Hg}$ higher than $1 \mathrm{mg} \mathrm{kg}$. Moreover, accessibility to this equipment is usually limited [6-8]. The Sequential Chemical Extraction (SCE) procedure which uses sequentially arranged solvents to extract $\mathrm{Hg}$ species into different liquid fractions has low detection limits. However, the main drawback of this method is the possible chemical alteration of the sample by the solvents, which decreases the selectivity of the method [9-11].

A promising technique with low detection limits is that based on thermal programmed desorption (HgTPD) [12-14]. Moreover, HgTPD is an easily accessible technique which can be implemented without the need for complicated instrumentation or for the time-consuming sample pre-treatment required by EXAFS and SCE. HgTPD is based on the low stability of $\mathrm{Hg}$ compounds at low temperatures, which allows mercury species to be identified by their characteristic temperatures of decomposition or desorption. Table 1 shows desorption temperatures for the main mercury compounds as described in the literature, obtained by using different experimental devices and conditions. The technique has been tested on a wide variety of solids, which include; sediments and soils [15-18], waste lamps [19], fly ashes [18,20], gypsum [21-23] and sorbents from $\mathrm{Hg}$ retention $[24,25]$. However, the validity of the method must remain open to doubt until the influence of several instrumental parameters upon the results has been clearly established. It should also be considered that, unlike EXAFS, HgTPD does not provide quantitative results for the different $\mathrm{Hg}$ phases present in samples. Some of the questions concern the overlapping of peaks, possibly related to the flow rate and 
heating rate, and the selection and preparation of the mercury reference compounds regarding the possible effects the matrix might have upon them.

To clarify these matters and to evaluate the robustness and reliability of the thermal desorption method for identifying mercury species in solids, this study evaluates the results provided by three HgTPD devices under different conditions using several types of solids from coal utilization processes. Once the reliability of the thermal desorption technique for identifying mercury species in samples free of carbon matter was verified, a new device capable of avoiding the interferences produced by carbon was included in the evaluation sequence. The new device is a modification of a commercial device already evaluated.

\section{Method and materials}

\subsection{Samples}

The samples studied were sub-products from coal combustion processes (fly ashes and gypsums), contaminated soils from the coal industry and a coal. The fly ashes, namely CTL, CTA and CTP, were obtained from two pulverized coal power plants and a fluidized bed combustion plant, respectively. The characteristics of these fly ashes have been described elsewhere [18]. Two samples of gypsum (Gypsum A and Gypsum Z) were collected from the Wet Flue Gas Desulfuration Plants (WFGD) of two 1200 MW power stations. These gypsum samples have been previously characterized by the authors [21]. The soil samples were collected from the surrounding area of a coking plant [26]. PUSH3 and FAR2 were taken from points close to, and outside, the area of greatest activity of the plant, respectively, whereas TDIST1 was sampled at the point of maximum mercury concentration [27]. The coal sample (CL-Sb) was a low rank coal. 
Eight commercial $\mathrm{Hg}$ compounds $\left(\mathrm{HgCl}_{2}, \mathrm{Hg}_{2} \mathrm{Cl}_{2}\right.$, black $\mathrm{HgS}$, red $\mathrm{HgS}, \mathrm{Hg}-\mathrm{HA}$ (humic acid), $\mathrm{HgO}, \mathrm{Hg}_{2} \mathrm{SO}_{4}$ and $\mathrm{HgSO}_{4}$ ) were blended by successive dilutions with different materials (silica flour, sand, fly ash, gypsum and a soil) in order to simulate different matrices until mercury concentrations of up to $10 \mathrm{mg} \cdot \mathrm{kg}^{-1}$ were obtained. Homogenization of the pure mercury compounds and the matrix was carried out by grinding the sample in a mortar to homogenize the particle size, and then using a rotary shaker to blend the solids. These blends were used as reference samples. It must be remembered that there are two different $\mathrm{HgS}$ crystalline structures: black $\mathrm{HgS}$ and red $\mathrm{HgS}$. The structure of red $\mathrm{HgS}$ is trigonal with $\mathrm{Hg}$ arranged on a rhombohedral lattice whereas the structure of black $\mathrm{HgS}$ is cubic. This fact may affect the desorption temperature. Therefore, both $\mathrm{HgS}$ compounds were studied. The mercury compounds were chosen as being the most likely species to be found in the type of solids evaluated. Additionally, a mercury reference material was prepared from humic acid, according to a previously described method [28]. The reference material, labelled in this paper either as $\mathrm{Hg}-\mathrm{OM}$ or $\mathrm{Hg}-\mathrm{HA}$, simulates possible linkages of mercury to organic and carbon matter in soils, coals and unburned carbon present in fly ashes [29,30]. It contains $\mathrm{COOH}, \mathrm{OH}$ and $\mathrm{CO}$ groups, the presence of which in coal depends on the rank of the coal. A sample of natural pyrite $\left(\mathrm{FeS}_{2}\right)$ was used as the reference compound for mercury associated to the pyrite $\left(\mathrm{Hg}-\mathrm{FeS}_{2}\right)$ present in the coal sample.

\subsection{Hg-thermo-desorption devices}

Three devices, designated as HgTPD-1, HgTPD-2 and HgTPD-3, operating in laboratories in Spain, Germany and United Kingdom, respectively, were used in this study to identify the mercury species by means of thermal programmed desorption (Figure 1).

HgTPD-1 consists of a continuous mercury analyzer (RA-915) coupled to a furnace 
(PYRO-915), both from Lumex (Figure 1a) [14]. The analyzer RA-915 operates on the basis of differential Zeeman atomic absorption spectrometry and high frequency modulation of light polarization. The PYRO-915 furnace consists of two chambers in series. The first chamber serves to pyrolyze the solid samples. In this chamber mercury compounds are released from the solid matrix in a controlled 3-step heating mode and an air flow of $1 \mathrm{~L} \cdot \mathrm{min}^{-1}$. The temperature rate was kept at $40{ }^{\circ} \mathrm{C} \min ^{-1}$ for $575 \mathrm{~s}$. Heating rate was then increased up to $50{ }^{\circ} \mathrm{C} \mathrm{min}^{-1}$, where it was held for $200 \mathrm{~s}$ and then up to 80 ${ }^{\circ} \mathrm{C} \min ^{-1}$ where it was held for a further $125 \mathrm{~s}$. The second chamber, which was kept at approximately $800^{\circ} \mathrm{C}$, served to reduce the mercury compounds to elemental mercury. The temperature of the sample was continuously monitored. The detection limit of the system was $1 \mathrm{ng}$ for a maximum sample weight of $100 \mathrm{mg}\left(0.01 \mathrm{mg} \mathrm{kg}^{-1}\right)$ assuming that all the $\mathrm{Hg}$ would be released within a single peak.

The HgTPD-2 device (Figure 1b) consists of an electronically controlled heating unit and a mercury detection unit [12]. For detection of mercury, a quartz cell, where the thermally released $\mathrm{Hg}^{0}$ was purged, was placed in the optical system of an atomic absorption spectrometer (Perkin Elmer AAS 3030), where Hg absorption was detected at $253.7 \mathrm{~nm}$ in continuous detection mode ( $1 \mathrm{~s}$ intervals). Measurements were carried out at a heating rate of $30{ }^{\circ} \mathrm{C} \cdot \mathrm{min}^{-1}$ and a $\mathrm{N}_{2}$ flow of $300 \mathrm{~mL} \cdot \mathrm{min}^{-1}$. All the released $\mathrm{Hg}$ compounds were transformed to $\mathrm{Hg}^{0}$ through thermal reduction by being made to pass through a quartz glass tube heated by a platinum coil $\left(800^{\circ} \mathrm{C}\right)$, and detected by AAS in continuous detection mode with D2-background correction. The detection limit of the system was $40 \mathrm{ng}$ for a maximum sample weight of $200 \mathrm{mg}\left(0.2 \mathrm{mg} \mathrm{kg}^{-1}\right)$ assuming that all the $\mathrm{Hg}$ would be released within a single peak [12].

HgTPD-3 consists of a thermal dissociation rig (PS Analytical Thermogram model 50.042) coupled to a mercury analyzer (PS Analytical Sir Galahad Mercury Analyzer 
model 10.525) (Figure 1c) [31]. The commercial thermal dissociation unit was modified to optimize the distribution of temperature along the work-tube between the programmed dissociation zone $\left(40-650^{\circ} \mathrm{C} \max \right)$ and the "cracker" zone (operated at $800^{\circ} \mathrm{C}$ ), where the volatilized mercury compounds were fully dissociated before being detected as elemental mercury by the atomic fluorescence detector. The mercury compounds present in the solid sample were subjected to a programmed rise in temperature of $10^{\circ} \mathrm{C} \cdot \mathrm{min}^{-1}$ and an Ar flow of $250 \mathrm{~mL} \cdot \mathrm{min}^{-1}$. The detection limit of the

device was $2 \mathrm{ng}$ for a maximum sample weight of $350 \mathrm{mg}\left(0.006 \mathrm{mg} \mathrm{kg}^{-1}\right)$ assuming that all the $\mathrm{Hg}$ would be released within a single peak.

\section{Results and discussion}

The results of this study are divided into three sections to facilitate discussion: (i) the characteristic desorption temperature for the reference mercury compounds; (ii) the speciation of mercury in samples with low carbon content (fly ashes, gypsums and soils) and (iii) the speciation of mercury in a coal sample.

\subsection{Reference mercury compounds}

The mercury species in the solid samples were identified on the basis of the temperature at which they were released. The reference materials prepared from pure mercury compounds were tested to determine their specific thermograms and maximum temperature of decomposition which serve subsequently as a standard of comparison for the profiles obtained from the solid samples. Table 2 summarizes the maximum temperature of decomposition (high peak temperature) in the three devices for each $\mathrm{Hg}$ reference material using silica powder as the sample matrix. The precision of the analysis was evaluated from the results of the standard deviation (SD) obtained after analyzing each sample three times. When the reference compounds were prepared using 
the same matrix of the samples studied (fly ash, gypsum and soil), the high-peak temperatures obtained were similar. Possible interferences or interactions during the thermal release of the different mercury species were discarded when several $\mathrm{Hg}$ compound mixtures were analysed [14]. The tests for speciation of mercury in the different matrices were carried out in HgTPD-1 in the case of fly ash, gypsum and soil samples and in HgTPD-3 for fly ash and gypsum. Regardless of the flow rate (from 250 to $1000 \mathrm{~mL} \mathrm{~min}{ }^{-1}$ ), carrier gas (inert or air) or heating ramp (from 10 to $80{ }^{\circ} \mathrm{C} \mathrm{min}^{-1}$ ), the temperature decomposition rate of the mercury species fell into the following increasing order: $\mathrm{Hg}_{2} \mathrm{Cl}_{2} \leq \mathrm{HgCl}_{2}<\mathrm{Hg}-\mathrm{FeS}_{2} \leq \mathrm{HgS}$ (black) $\leq \mathrm{Hg}-\mathrm{HA}<\mathrm{HgS}$ (red) $<$ $\mathrm{Hg}_{2} \mathrm{SO}_{4}<\mathrm{HgO}<\mathrm{HgSO}_{4}$ in all three devices using silica powder as matrix (Table 2).

Taking into account the standard deviation of the results, no significant differences were observed in the identification of mercury compounds. However, the following variations were detected in the maximum temperature of desorption: 1) in general, the temperatures of desorption obtained with HgTPD-2 were slightly higher than those of HgTPD-1 and -3. These differences may be related to the position of the thermocouple that controls the temperature of the sample. In the case of HgTPD-2 the thermocouple is placed vertically in contact with the sample (Figure 1b). However, in devices HgTPD-1 and -3 the thermocouple is horizontally positioned inside the sample boat, but not in direct contact with the whole sample (Figure 1a and c); 2) $\mathrm{Hg}_{2} \mathrm{Cl}_{2}$ shows one decomposition peak in HgTPD-1 whereas there are two peaks in HgTPD-2 and -3. As already explained in previous works [19,31], the two peaks are probably a consequence of the decomposition of $\mathrm{Hg}_{2} \mathrm{Cl}_{2}$ in two steps:

$$
\begin{aligned}
& \mathrm{Hg}_{2} \mathrm{Cl}_{2} \rightarrow \mathrm{Hg}^{0}+\mathrm{HgCl}_{2} \\
& \mathrm{HgCl}_{2} \rightarrow \mathrm{Hg}^{0}+\mathrm{Cl}_{2}
\end{aligned}
$$


the second peak of $\mathrm{Hg}_{2} \mathrm{Cl}_{2}$ being close to the temperature of decomposition of $\mathrm{HgCl}_{2}$ in HgTPD-2 and -3 (Table 2). Failure to resolve the decomposition peaks of $\mathrm{Hg}_{2} \mathrm{Cl}_{2}$ in HgTPD-1 is a consequence of the higher flow rate $\left(1000 \mathrm{~mL} \mathrm{~min}^{-1}\right)$ used in this device; 3) the thermograms obtained for metacinnabar or black HgS may show two small peaks at the top of the profile in HgTPD-3, as was previously observed by Lopez-Anton et al. [31]. However, this compound decomposes at approximately $200^{\circ} \mathrm{C}$ in all cases and 4) the species $\mathrm{HgO}$ and $\mathrm{Hg}_{2} \mathrm{SO}_{4}$ both start and end decomposing at similar temperatures in all three devices. However, when the experiments are running at the lowest heating rate, as in the case of $\operatorname{HgTPD}-3\left(10^{\circ} \mathrm{C} \min ^{-1}\right)$, the profile presents only one peak, which corresponds to the main peak identified in the other two devices. The secondary peaks in the HgTPD-1 and HgTPD-2 thermograms are indicated in parenthesis in Table 2.

In summary, the results show that mercury compounds decompose in the same order in all three experimental devices, the small differences observed being due to the specific experimental conditions of each device. Therefore, each device needs to be precalibrated to be able to accurately assign to each mercury compound its characteristic temperature of desorption.

\section{2. $\quad$ Mercury species in samples with a low carbon content}

Table 3 compares the mercury species identified by the three devices in all the samples studied. Because the coal sample can only be analysed using the modified HgTPD-1 equipment, the results for coal will be evaluated in a separate section. Discussion of the different mercury compounds identified in each type of sample (Table 3) is not a matter for this work and has already been described in previous studies carried out in HgTPD-1 by the authors [18,23]. Nevertheless, it is worth mentioning that in those studies red $\mathrm{HgS}$ and mercury bound to unburned particles (namely either $\mathrm{Hg}$ - 
$\mathrm{OM}$ or $\mathrm{Hg}$-HA), were the main species present in the fly ashes. $\mathrm{HgSO}_{4}$ was also found in the fly ash produced in the fluidized bed combustion power plant. In the soil samples, red $\mathrm{HgS}$ and mercury bound to humic acids (Hg-HA) were the main species identified, whereas black $\mathrm{HgS}$ was the main species found in the gypsum samples.

The present study is mainly focused on evaluating how the identification of mercury species by thermal desorption might be influenced by the experimental conditions and the characteristics of the equipment. As can be seen in Table 3, regardless of the number of species detected in each sample with each equipment, there are no discrepancies in the type of species identified.

In view of these results, several points need to be made regarding the thermal desorption technique:

a) Detection limit: In some samples, because they were in small concentrations, mercury species such as $\mathrm{HgSO}_{4}, \mathrm{HgCl}_{2}$ and $\mathrm{HgO}$, could not be identified by the HgTPD-2 device (Table 3), since it has a higher detection limit $\left(0.2 \mathrm{mg} \mathrm{Kg}^{-1}\right)$ than HgTPD-1 (0.01 mg Kg $\left.{ }^{-1}\right)$ and HgTPD-3 (0.006 mg Kg$\left.{ }^{-1}\right)$. The detection limit was calculated by analyzing a blank 10 times taking into account the average of these results and the standard deviation. It should also be mentioned that the detection limit was always calculated assuming that all mercury is released within a single peak. If a thermogram shows multiple peaks, this means that the detection limit has decreased.

b) Heating ramp: One of the most important variables when thermal desorption is used to identify mercury species is the effect of the heating ramp on the high-peak temperature obtained for each mercury compound. The usual heating rate ranges from 10 to $50{ }^{\circ} \mathrm{C} \min ^{-1}$ (Table 1 ). In this study 10,30 and $40-80{ }^{\circ} \mathrm{C} \min ^{-1}$ were used 
in each case bearing in mind that the heating ramp in the experimental device needs to be optimized to obtain the best possible resolution peak. It should be mentioned that a low heating rate does not necessarily favor peak resolution. In fact, in the equipment that will be described in the following section (HgTPD-1B) the heat rate was tested from 10 to $50{ }^{\circ} \mathrm{C} \mathrm{min}^{-1}$ and the best peak resolution was obtained at 50 ${ }^{\circ} \mathrm{C} \min ^{-1}$.

c) Carrier gas and flow rate: Although in the case of the fly ashes, gypsums and soils studied, these parameters did not affect the identification of mercury species, a high carrier gas flow rate $\left(1000 \mathrm{~mL} \mathrm{~min}^{-1}\right)$ may reduce the sensitivity of the equipment, causing peaks to overlap for some mercury species. For example, $\mathrm{Hg}_{2} \mathrm{Cl}_{2}$ presents one peak in the profile obtained with HgTPD-1, whereas in HgTPD-2 (300 mL $\left.\min ^{-1}\right)$ and HgTPD-3 (250 mL min $\left.{ }^{-1}\right)$ the thermogram shows two peaks (Table 2). It should be pointed out that HgTPD-1 cannot work at a flow rate lower than 1000 $\mathrm{mL} \min ^{-1}$.

d) Type of gas. Inert gases are generally used in this type of equipment, but HgTPD-1 uses air instead of $\mathrm{N}_{2}$ or Ar as carrier gas. The carrier gas can affect mercury detection in samples with a large amount of carbon matter, as will be discussed in the following section.

\section{3. $\quad$ Mercury species in the coal sample}

The identification of mercury species in the coal sample using HgTPD-2 and HgTPD-3 was not possible due to interferences with the mercury detector signal resulting from the pyrolysis products released during heating coal in the inert atmosphere. Therefore, air was employed as carrier gas in HgTPD-1 to oxidize the carbon compounds in the gas phase. However, uncontrolled reactions may take place 
during decomposition or desorption of the mercury species in air influencing the specific temperature for each species. For this reason we constructed a new set-up [32] based on a modification of HgTPD-1 and labelled HgTPD-1B (Figure 2).

The HgTPD-1B device consisted of a new thermo-desorption furnace coupled to the PYRO 915 furnace and the continuous mercury analyzer (RA-915). The novelty of this device is that in the new furnace the desorption of mercury species is carried out using $\mathrm{N}_{2}$ an inert gas to avoid interferences, while at the same time $\mathrm{O}_{2}$ is introduced in the commercial PYRO furnace to ensure that the decomposition of the volatile matter from coal is completed. The new furnace consists of two chambers, in the first of which desorption of the mercury species occurs, while the second chamber ensures that the temperature is maintained to avoid cool zones and the condensation of $\mathrm{Hg}$ until it enters the PYRO furnace. The new furnace also contains two temperature controllers that allow the heating ramp and the temperature in the zone between the new and PYRO furnace to be optimized. The sample is weighed in a sample boat and its temperature is controlled by a thermocouple, as in the unmodified HgTPD-1 equipment. Moreover, in HgTPD-1B, the sample boat is placed inside a quartz tube to avoid any loss of mercury during the decomposition of the sample until it reaches the analyzer. Measurements are carried out at a heating rate of $50{ }^{\circ} \mathrm{C} \cdot \mathrm{min}^{-1}$ and a $\mathrm{N}_{2}$ flow of $500 \mathrm{~mL} \cdot \mathrm{min}^{-1}$. The PYRO 915 unit is kept at $800{ }^{\circ} \mathrm{C}$ under an $\mathrm{O}_{2}$ flow of $500 \mathrm{~mL} \cdot \mathrm{min}^{-1}$. The detection limit of the system was $3 \mathrm{ng}$ for a maximum sample weight of $100 \mathrm{mg}\left(0.03 \mathrm{mg} \mathrm{kg}^{-1}\right)$ assuming that all the $\mathrm{Hg}$ would be released within a single peak. The accuracy of the results for total mercury content was verified by analyzing a standard coal (SARM 19) with a total mercury content of $0.20 \mathrm{mg} \mathrm{kg}$. The result was $0.23 \pm 0.3 \mathrm{mg} \mathrm{kg}^{-1}$ with a relative standard deviation of less than $10 \%$. 
Figure 3 contrasts the thermograms obtained for the coal sample (CL-Sb) using the HgTPD-1 and HgTPD-1B devices. As can be seen, one single peak from 100 to $300^{\circ} \mathrm{C}$ with a maximum signal at around $180^{\circ} \mathrm{C}$ was obtained when the analysis was performed in the HgTPD-1 device, whereas two main peaks at approximately 165 and $215^{\circ} \mathrm{C}$ were recorded in HgTPD-1B. In this way a higher peak resolution was attained with the new set-up that enabled us to detect $\mathrm{Hg}-\mathrm{FeS}_{2}\left(169^{\circ} \mathrm{C}\right)$ and $\mathrm{Hg}$ bound to organic matter $(\mathrm{Hg}$ $\mathrm{OM})\left(220^{\circ} \mathrm{C}\right)$ (Table 2). In short, the new HgTPD-1B device developed by the authors [32] is able to identify mercury species in coals, preparing the way for a more extensive study on the identification of mercury in different types of coals and carbonaceous materials, a task that until now has proved to be very difficult by means of other techniques.

\section{Conclusions}

This work has demonstrated that the HgTPD technique is a sensitive and selective method for identifying mercury species in solids. Although the technique does not answer all questions about $\mathrm{Hg}$ speciation (semi-quantitative analysis), the results obtained using different devices are reproducible. A comparison of the devices shows that the main difference in their mercury species identification capacity lies in the detection limits of their detectors.

The commercial equipment currently available is subject to serious limitations for carrying out analyses of coal samples. These limitations were overcome in this work by using a modified device for coal samples. The new equipment fitted with two furnaces and two gas inlets facilitates the identification of mercury species in coals, preparing the 
way for a more extensive study on the identification of mercury in different types of coals and carbonaceous materials.

\section{Acknowledgments}

The authors are grateful to the National Research Program under project CTM201122921 and thank the Spanish Research Council (CSIC) for awarding Ms. Marta Rumayor a JAE-predoc fellowship and for financing her stay at the Technische Universität Braunschweig, Institut für Geoökologie (Germany).

\section{References}

[1] United National Environmental Programme (UNEP), 2013; http://www.mercuryconvention.org/Home/tabid/3360/Default.aspx

[2] N. Pirrone, S. Cinnirella, X. Feng, R.B. Finkelman, H.R. Friedli, J. Leaner, R. Mason, A.B. Mukherjee, G.B. Stracher, D.G. Streets, K. Telmer, Global mercury emissions to the atmosphere from anthropogenic and natural sources, Atmospheric Chemistry and Physics Discussions. 10 (2010) 5951-5964.

[3] M. Rallo, M.A. López-Antón, M.L. Contreras, M.M. Maroto-Valer, Mercury policy and regulations for coal-fired power plants, Environ. Sci. Pollut. R. 19 (2012) 10841096.

[4] European Pollutant Release and Transfer Register (E-PRTR), 2012; $\underline{\text { http://prtr.ec.europa.eu/Home.aspx }}$

[5] A. Fuente-Cuesta, M.A. Lopez-Anton, M. Diaz-Somoano, M.R. Martinez-Tarazona, Retention of mercury by low-cost sorbents: Influence of flue gas composition and fly as occurrence, Chem. Eng. J. 213 (2012) 16-21. 
[6] F.E. Huggins, N. Yap, G.P. Huffman, C.L. Senior, XAFS characterization of mercury captured from combustion gases on sorbents at low temperatures, Fuel Process. Technol. 82 (2003) 167-196.

[7] C.S. Kim, N.S. Bloom, J.J. Rytuba, G.E. Brown, Mercury Speciation by X-ray Absorption Fine Structure Spectroscopy and Sequential Chemical Extractions: A Comparison of Speciation Methods, Environ. Sci. Technol. 37 (2003) 5102-5108.

[8] C.S. Kim, J.J. Rytuba, G.E. Brown, EXAFS study of mercury(II) sorption to Fe- and Al-(hydr)oxides II. Effects of chloride and sulfate, J. Colloid Interf. Sci. 270 (2004) 9-20.

[9] N.S. Bloom, E. Preus, J. Katon, M. Hiltner, Selective extractions to assess the biogeochemically relevant fractionation of inorganic mercury in sediments and soils, Anal. Chim. Acta 479 (2003) 233-248.

[10] Y. Han, H.M. Kingston, H.M. Boylan, G.M.M. Rahman, S. Shah, R.C. Richter, D.D. Link, S. Bhandari, Speciation of mercury in soil and sediment by selective solvent and acid extraction, Anal. Bioanal. Chem. 375 (2003) 428-436.

[11]N. Issaro, C. Abi-Ghanem, A. Bermond, Frationation studies of mercury in soils and sediments: A review of the chemical reagents used for mercury extraction, Anal. Chim. Acta 631 (2009) 1-12.

[12]H. Biester, C. Scholz, Determination of Mercury Binding Forms in Contaminated Soils: Mercury Pyrolysis versus Sequential Extractions, Environ. Sci. Technol. 31 (1996) 233-239.

[13] A.T. Reis, J.P. Coelho, S.M. Rodrigues, R. Rocha, C.M. Davidson, A.C. Duarte, E. Pereira, Development and validation of a simple thermo-desorption technique for mercury speciation in soils and sediments, Talanta 99 (2012) 363-638. 
[14] M. Rumayor, M. Díaz-Somoano, M.A. López-Antón, M.R. Martínez-Tarazona, Mercury compounds characterization by thermal desorption, Talanta 114 (2013) 318-322.

[15]H. Biester, M. Gosar, G. Müller, Mercury speciation in tailings of the Idrija mercury mine, J. Geochem. Explor. 65 (1999) 195-204.

[16]H. Biester, M. Gosar, S. Covelli, Mercury Speciation in Sediments Affected by Dumped Mining Residues in the Drainage Area of the Idrija Mercury Mine, Slovenia, Environ. Sci. Technol. 34 (2000) 3330-3336.

[17]H. Biester, G. Müller, H. F. Schöler, Binding and mobility of mercury in soils contaminated by emissions from chlor-alkali plants, Sci. Total Environ. 284 (2002) 191-203.

[18]M. Rumayor, M. Diaz-Somoano, M.A. Lopez-Anton, M.R. Martinez-Tarazona, Application of thermal desorption for the identification of mercury species in solids derived from coal utilization, Chemosphere 119 (2015) 459-465.

[19]C. Raposo, C.C. Windmöller, W.A.D. Junior, Mercury speciation in fluorescent lamps by thermal release analysis, Waste Manage. 23 (2003) 879-886.

[20]M.A. López-Antón, R. Perry, P. Abad-Valle, M. Díaz-Somoano, M.R. MartínezTarazona, M.M. Maroto-Valer, Speciation of mercury in fly ashes by temperature programmed decomposition, Fuel Process. Technol. 92 (2011) 707-711.

[21]M. Rallo, M.A. López-Antón, R. Perry, M.M. Maroto-Valer, Mercury speciation in gypsums produced from flue gas desulfurization by temperature programmed decomposition, Fuel 89 (2010) 2157-2159.

[22]X. Liu, S. Wang, L. Zhang, Y. Wu, L. Duan, J. Hao, Speciation of mercury in FGD gypsum and mercury emission during the wallboard production in China, Fuel 111 (2013) 621-627. 
[23] M. Rumayor, M. Díaz-Somoano, M.A. López-Antón, R. Ochoa-González, M.R. Martínez-Tarazona, Temperature programmed desorption as a tool for the identification of mercury fate in WFGD systems, Fuel 148 (2015) 98-103.

[24] M. Ozaki, Md.A. Uddin, E. Sasaoka, S. Wu, Temperature programmed decomposition desorption of the mercury species over spent iron-based sorbents for mercury removal from coal derived fuel gas, Fuel 87 (2008) 3610-3615.

[25] M. Rumayor, N. Fernandez-Miranda, M.A. López-Antón, M. Diaz-Somoano, M.R. Martinez-Tarazona, Application of mercury temperature programmed desorption (HgTPD) to ascertain mercury/char interactions, Fuel Process. Technol. 132 (2015) $9-14$.

[26] M. Díaz-Somoano, M.A. López-Antón, I. Suárez-Ruiz, M. Calvo, S. Suárez, R. García, M.R. Martínez-Tarazona, Impact of a semi-industrial coke processing plant in the surrounding surface soil Part I: Trace element content, Fuel Process. Technol. $102(2012) 35-45$.

[27] M. Díaz-Somoano, M. Calvo, M.A. López-Antón, I. Suarez-Ruiz, R. Garcia, S.R. Moinelo, M.R. Martinez-Tarazona, Lead isotope ratios in a soil from a coal carbonization plant, Fuel 86 (2007) 1079-1085.

[28] R. Terzano, A. Santoro, M. Spagnuolo, B. Vekemans, L. Medici, K. Janssens, J. Gottlicher, M.A. Denecke, S. Mangold, P. Ruggiero, Solving mercury (Hg) speciation in soil samples by synchrotron X-ray microspectroscopic techniques, Environ. Pollut. 158 (2010) 2702-2709.

[29] Y.E. Yudovich, M.P. Ketris, Mercury in coal: a review Part 1. Geochemistry, Int. J. Coal Geol. 62 (2005) 107-134. 
[30]L.Y. Kizil'shtein, A.G. Peretyat'ko, G.I. Gofen, Concentration of impurity elements in coals from aspects of the concept of hard and soft acids and bases, Khim. Tverd. Topl. (Chem. Solid Fuels) 23(2) (1989) 132-138.

[31] M.A. Lopez-Anton, Y. Yuan, R. Perry, M.M. Maroto-Valer, Analysis of mercury species present during coal combustion by thermal desorption, Fuel 89 (2010) 629634.

[32] M. Rumayor, M.A. López-Antón, M. Díaz-Somoano, M.R. Martínez-Tarazona, Device for identification of mercury species in solids. Consejo Superior de Investigaciones Científicas (CSIC). Patent ES1641.1031 Application number: P201530310 (2015).

[33] C.C. Windmöller, R.D. Wilken, W.F. Jardim, Mercury speciation in contaminated soils by thermal release analysis, Water Air Soil Poll. 89 (1996) 399-416.

[34]J.Y. Lee, K. Cho, L. Cheng, T.C. Keener, G. Jegadeesan, S.R. Al-Abed, Investigation of a mercury speciation technique for flue gas desulfurization materials, J. Air Waste Manage. Assoc. 59 (2009) 972-979.

[35] X. Feng, J.Y. Lu, D.C. Grégoire, Y. Hao, C.M. Banic, W.H. Schroeder, Analysis of inorganic mercury species associated with airborne particulate matter/aerosols: method development, Anal. Bioanal. Chem. 380 (2004) 683-689.

[36]P. Coufalík, P. Krásenský, M. Dosbaba, J. Komárek, Sequential extraction and thermal desorption of mercury from contaminated soil and tailings from Mongolia, Eur. J. Chem. 10(5) (2012) 1565-1573.

[37] S. Wu, Md.A. Uddin, N. Saori, M. Ozaki, E. Sasaoka, Fundamental Study on Decomposition Characteristics of Mercury Compounds over Solid Powder by Temperature-Programmed Decomposition Desorption Mass Spectrometry, Energ.
Fuel.
25
(2011)
144-153. 
Table 1. High peak desorption temperatures of mercury compounds obtained in different solid matrices and experimental conditions

\begin{tabular}{|c|c|c|c|c|c|c|}
\hline Hg species & $\begin{array}{c}\text { High T } \\
\left({ }^{\circ} \mathrm{C}\right)\end{array}$ & Solid matrix & $\begin{array}{c}\text { Heat rate } \\
\left({ }^{\circ} \mathrm{C} / \mathrm{min}\right)\end{array}$ & $\begin{array}{c}\text { Carrier gas } \\
(\mathrm{ml} / \mathrm{min})\end{array}$ & Detector & $\begin{array}{c}\text { DL } \\
\left(\mathrm{mg} \mathrm{kg}^{-1}\right)\end{array}$ \\
\hline \multirow[t]{4}{*}{$\mathrm{Hg}_{2} \mathrm{Cl}_{2}$} & 160 & Soil & 10 & $\mathrm{~N}_{2}(100)$ & AAS [33] & 0.03 \\
\hline & $225-350$ & Phosphorus & 33 & $\mathrm{~N}_{2}(200)$ & AAS [19] & --- \\
\hline & 190 & - & 5 & $\mathrm{~N}_{2}(2000)$ & CVAAS [34] & 0.05 \\
\hline & 148 and & gypsum & 10 & $\mathrm{~N}_{2}(400)$ & AAS [22] & 0.002 \\
\hline \multirow[t]{6}{*}{$\mathrm{HgCl}_{2}$} & 263 & Soil & 10 & $\mathrm{~N}_{2}(100)$ & AAS [33] & 0.03 \\
\hline & 275 & Phosphorus & 33 & $\mathrm{~N}_{2}(200)$ & AAS [19] & --- \\
\hline & 120 & Fly ash & 50 & $\operatorname{Ar}(1000)$ & ICP-MS [35] & 0.000005 \\
\hline & $100-220$ & Sand & 30 & $\operatorname{Ar}(500)$ & AAS [36] & 0.5 \\
\hline & 145 & - & 5 & $\mathrm{~N}_{2}(2000)$ & CVAAS [34] & 0.05 \\
\hline & 212 & gypsum & 10 & $\mathrm{~N}_{2}(400)$ & AAS [22] & 0.002 \\
\hline \multirow{2}{*}{$\begin{array}{l}\mathrm{Hg}-\mathrm{HA} \\
\text { (Hg-OM) }\end{array}$} & $260-350$ & Sand & 30 & $\operatorname{Ar}(500)$ & AAS [36] & 0.5 \\
\hline & $100-240$ & Aluminium oxide & & Air & AAS [13] & 0.02 \\
\hline \multirow[t]{2}{*}{ Black HgS } & 250 & quartz sand & 10 & $\mathrm{~N}_{2}(250)$ & AAS [24] & --- \\
\hline & $180-350$ & silica & & $\mathrm{He}$ & [37] & ---- \\
\hline \multirow[t]{6}{*}{ Red HgS } & 350 & quartz sand & 10 & $\mathrm{~N}_{2}(250)$ & AAS [24] & ---- \\
\hline & $250-430$ & Sand & 30 & $\operatorname{Ar}(500)$ & AAS [36] & 0.5 \\
\hline & 350 & Fly ash & 50 & $\operatorname{Ar}(1000)$ & ICP-MS [35] & 0.000005 \\
\hline & $250-400$ & silica & & $\mathrm{He}$ & [37] & --- \\
\hline & 290 & - & 5 & $\mathrm{~N}_{2}(2000)$ & CVAAS [34] & 0.05 \\
\hline & 350 & gypsum & 10 & $\mathrm{~N}_{2}(400)$ & AAS [22] & 0.002 \\
\hline \multirow[t]{5}{*}{$\mathrm{HgO}$} & 300 & Soil & 10 & $\mathrm{~N}_{2}(100)$ & AAS [33] & 0.03 \\
\hline & 400 & Phosphorus & 33 & $\mathrm{~N}_{2}(200)$ & AAS [19] & ---- \\
\hline & 500 & Fly ash & 50 & $\operatorname{Ar}(1000)$ & ICP-MS [35] & 0.000005 \\
\hline & 540 & - & 5 & $\mathrm{~N}_{2}(2000)$ & CVAAS [34] & 0.05 \\
\hline & $200-380$ & silica & & $\mathrm{He}$ & [37] & --- \\
\hline $\mathrm{Hg}_{2} \mathrm{SO}_{4}$ & $145-225$ & gypsum & 10 & $\mathrm{~N}_{2}(400)$ & AAS [22] & 0.002 \\
\hline \multirow[t]{3}{*}{$\mathrm{HgSO}_{4}$} & 400 & gypsum & 10 & $\mathrm{~N}_{2}(400)$ & AAS [22] & 0.002 \\
\hline & 580 & silica & & $\mathrm{He}$ & [37] & --- \\
\hline & 580 & - & 5 & $\mathrm{~N}_{2}(2000)$ & CVAAS [34] & 0.05 \\
\hline
\end{tabular}


Table 2. High peak temperatures of mercury compounds obtained in HgTPD-1, HgTPD-2 and HgTPD-3 devices.

\begin{tabular}{lccc}
\hline & \multicolumn{3}{c}{ High peak Temperature ( $\left.{ }^{\circ} \mathbf{C}\right)$} \\
\cline { 2 - 4 } & HgTPD-1 $[14,18,23]$ & HgTPD-2 & HgTPD-3 [31] \\
\hline $\mathrm{Hg}_{2} \mathrm{Cl}_{2}$ & $119 \pm 9$ & $102 \pm 3 ; 183 \pm 1$ & $80 \pm 5 ; 130 \pm 10$ \\
\hline $\mathrm{HgCl}_{2}$ & $138 \pm 4$ & $206 \pm 6$ & $120 \pm 10$ \\
\hline $\mathrm{Hg}-\mathrm{FeS}$ & & $259 \pm 3$ & $\mathrm{NA}$ \\
\hline $\mathrm{Hg}-\mathrm{HA}(\mathrm{Hg}-\mathrm{OM})$ & $220 \pm 5$ & $229 \pm 3$ & $\mathrm{NA}$ \\
\hline $\mathrm{Black} \mathrm{HgS}$ & $190 \pm 11$ & $217 \pm 3$ & $205 \pm 5 ;(245 \pm 5)$ \\
\hline $\mathrm{Red} \mathrm{HgS}$ & $305 \pm 12$ & $312 \pm 1$ & $310 \pm 10$ \\
\hline $\mathrm{HgO}$ & $(308 \pm 1) ; 471 \pm 5$ & $(336 \pm 3) ; 494 \pm 8$ & $505 \pm 5$ \\
\hline $\mathrm{Hg}_{2} \mathrm{SO}_{4}$ & $295 \pm 4 ;(514 \pm 4)$ & $315 \pm 3 ;(448 \pm 1)$ & $280 \pm 10$ \\
\hline $\mathrm{HgSO}_{4}$ & $583 \pm 18$ & $585 \pm 1$ & $540 \pm 20$ \\
\hline
\end{tabular}

NA: sample not available 
Table 3. Species of mercury identified in fly ashes, gypsums, soils and coal by three thermo-desorption devices.

\begin{tabular}{|c|c|c|c|c|c|}
\hline & \multirow{2}{*}{ Sample name } & \multirow{2}{*}[\mathrm{Hg}]{$\mathrm{mg} \mathrm{kg}^{-1}$} & \multicolumn{3}{|c|}{ High peak $\mathrm{T}\left({ }^{\circ} \mathrm{C}\right)$ (Hg Species) } \\
\hline & & & HgTPD-1 $[18,23]$ & HgTPD-2 & HgTPD-3 $[20,21]$ \\
\hline \multirow[t]{2}{*}{ Fly ash } & CTL & $0.42 \pm 0.02$ & $316^{\circ} \mathrm{C}(\mathrm{red} \mathrm{HgS}) ; 410^{\circ} \mathrm{C}(\mathrm{HgO}) \downarrow \downarrow$ & $314^{\circ} \mathrm{C}($ red $\mathrm{HgS})$ & $270^{\circ} \mathrm{C}($ red $\mathrm{HgS})$ \\
\hline & СТP & $1.10 \pm 0.11$ & $\begin{array}{c}190^{\circ} \mathrm{C}(\mathrm{Hg}-\mathrm{OM}) ; 295^{\circ} \mathrm{C}(\text { red HgS }) ; \\
420^{\circ} \mathrm{C}(\mathrm{HgO}) \downarrow \downarrow ; 630(\mathrm{HgSO} 4) \downarrow\end{array}$ & $200^{\circ} \mathrm{C}(\mathrm{Hg}-\mathrm{OM}) ; 309^{\circ} \mathrm{C}(\mathrm{red} \mathrm{HgS})$ & $\begin{array}{c}205^{\circ} \mathrm{C}(\mathrm{Hg}-\mathrm{OM}) ; 285^{\circ} \mathrm{C}(\text { red } \mathrm{HgS}) \\
600^{\circ} \mathrm{C}(\mathrm{HgSO} 4)\end{array}$ \\
\hline Gypsum & Gypsum A & $1.72 \pm 0.17$ & $190^{\circ} \mathrm{C}($ black $\mathrm{HgS})$ & $219^{\circ} \mathrm{C}$ (black HgS) & NA \\
\hline \multirow{2}{*}{ Soil } & PUSH3 & $1.33 \pm 0.15$ & $201^{\circ} \mathrm{C}(\mathrm{Hg}-\mathrm{HA}) ; 300^{\circ} \mathrm{C}($ red $\mathrm{HgS})$ & $194^{\circ} \mathrm{C}(\mathrm{Hg}-\mathrm{HA}) ; 270^{\circ} \mathrm{C}($ red $\mathrm{HgS})$ & NA \\
\hline & FAR2 & $0.14 \pm 0.01$ & $\begin{array}{c}120^{\circ} \mathrm{C}(\mathrm{HgCl} 2) \downarrow ; 202^{\circ} \mathrm{C}(\mathrm{Hg}-\mathrm{HA}) \\
300^{\circ} \mathrm{C}(\text { red } \mathrm{HgS})\end{array}$ & $213^{\circ} \mathrm{C}(\mathrm{Hg}-\mathrm{HA})$ & NA \\
\hline Coal & CL-Sb & $0.11 \pm 0.01$ & $170^{\circ} \mathrm{C}(\mathrm{Hg}-\mathrm{FeS} 2)$ & $\mathrm{X}$ & $\mathrm{X}$ \\
\hline
\end{tabular}

$\downarrow$ : Minor Hg species; NA: sample not available; X: no detection 


\section{Figure captions}

Figure 1. Schematic diagrams of $\mathrm{Hg}$ thermo-desorption devices: (a) HgTPD-1; (b) HgTPD-2 and (c) HgTPD-3

Figure 2. Schematic diagram of a new $\mathrm{Hg}$ thermo-desorption device (HgTPD-1B)

Figure 3. Thermal profile of coal sample CL-Sb obtained in the HgTPD-1 and HgTPD$1 \mathrm{~B}$ devices 
(a)

Detector $\mathrm{Hg}^{0}$

(Zeeman-AAS)
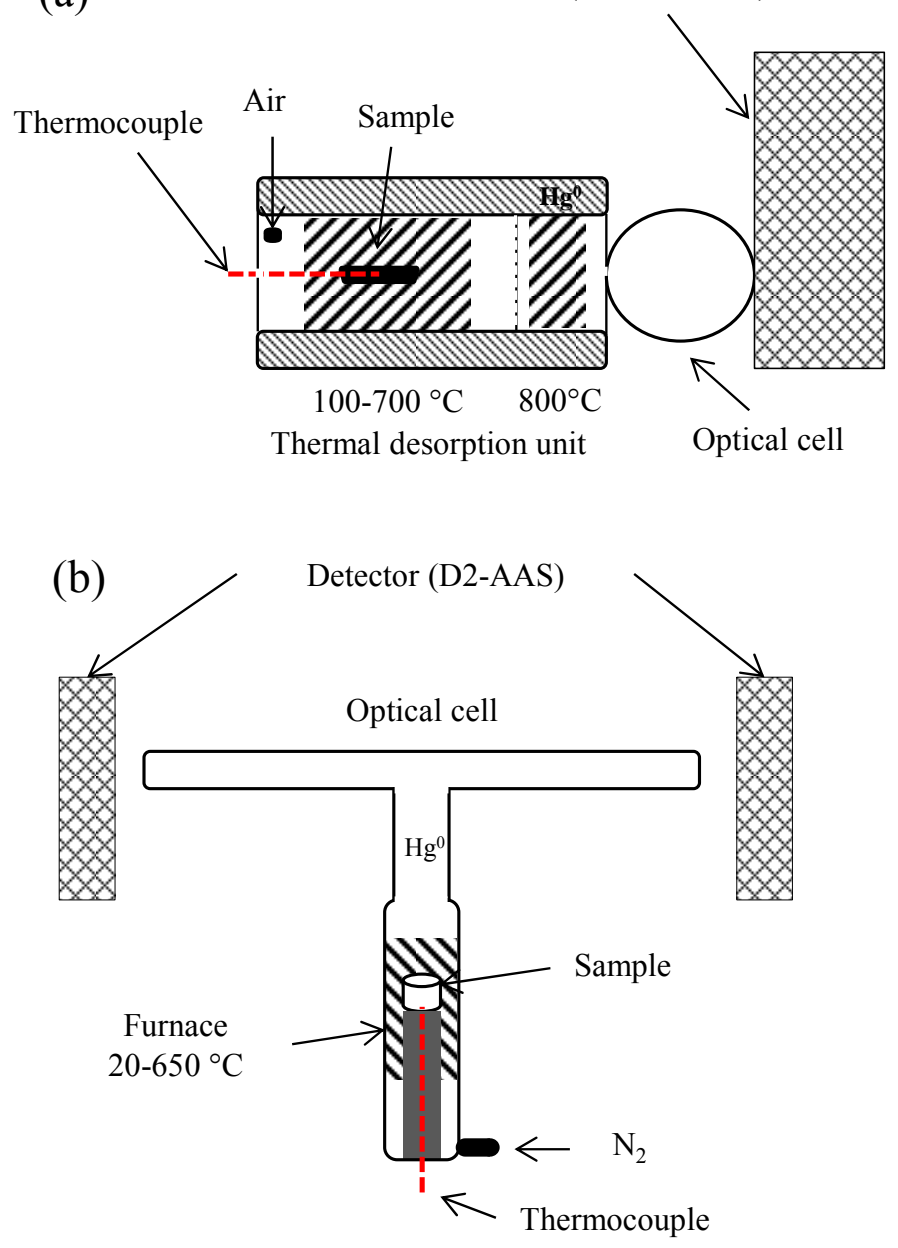

(c)

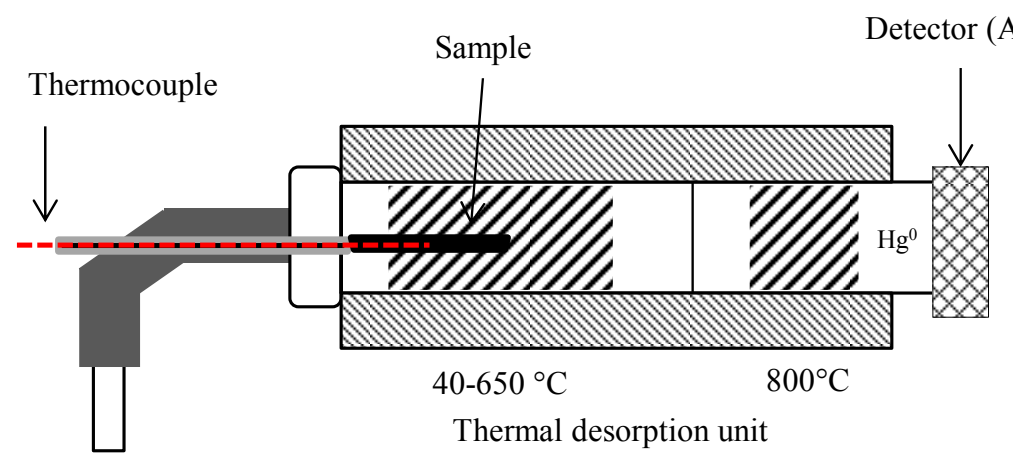

$\uparrow$ 
Figure 1

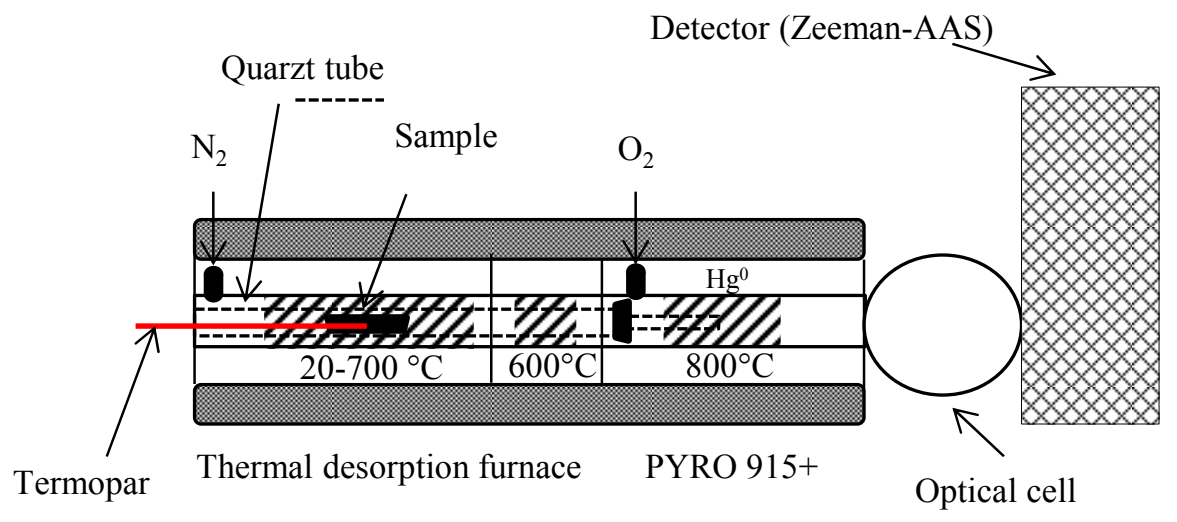

Figure 2 


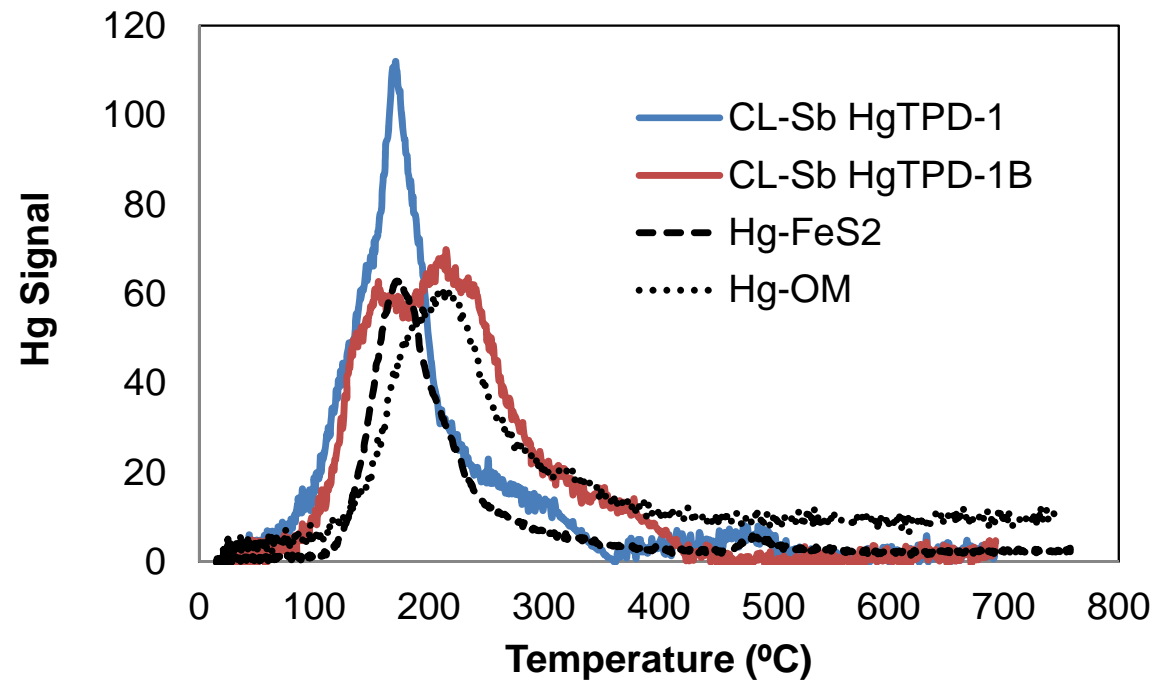

Figure 3 